\title{
Avaliação do perfil metabólico de touros em diferentes fases do ciclo reprodutivo
}

Marcelo Brandi VIEIRA ${ }^{1}$ Elizabeth SCHWEGLER ${ }^{1}$ Maikel Alan GOULART ${ }^{1}$ Viviane Maciel da SILVA² Jacques LESTON ${ }^{3}$ Vinícius Coitinho TABELEÃO' José Acélio da FONTOURA JÚNIOR ${ }^{4}$

Francisco Augusto Burkert DEL PINO ${ }^{5}$

Marcio Nunes CORRÊA ${ }^{6}$

\section{Correspondência para:}

Marcio Nunes Corrêa, Universidade Federal de Pelotas, Faculdade de Veterinária - Campus Universitário 96010900 - Pelotas/RS, Brasil. marcio.nunescorrea@gmail.com; nupeec@ufpel.edu.br;

www.ufpel.edu.br/nupeec

Recebido para publicação: 30/03/2007 Aprovado para publicação: 29/10/2009

\author{
1 - Médico Veterinário, Mestre em Veterinária - UFPel, Pelotas-RS \\ 2 - Química, Mestre em Química - UFPel, Pelotas-RS \\ 3 - Médico Veterinário, Santa Vitória do Palmar-RS \\ 4 - Zootecnista, Doutor em Zootecnia - UNIPAMPA, Dom Pedrito-RS \\ 5 - Farmacêutico e Bioquímico, Doutor em Bioquímica, UFPel, Pelotas-RS \\ 6 - Médico Veterinário, Doutor em Biotecnologia, UFPel, Pelotas-RS
}

\section{Resumo}

Os touros compóem uma importante categoria animal nos sistemas de produção ligados à pecuária, sendo responsáveis por uma considerável parcela do melhoramento genético de um rebanho. Porém, poucos estudos relacionados às condiçóes metabólicas desta categoria vêm sendo conduzidos. O objetivo deste estudo foi avaliar o perfil metabólico de touros em três períodos distintos do ciclo reprodutivo - antes da estação reprodutiva, durante e após a estação reprodutiva. Este experimento foi conduzido em uma propriedade da regiáo Sul do Rio Grande do Sul com 23 touros. Os marcadores bioquímicos utilizados para avaliar o perfil metabólico foram os seguintes: glicose, colesterol, para determinar o perfil energético; albumina, ureia, como marcadores proteicos e a enzima aspartato aminotransferase (AST) como indicador da função hepática. Os resultados demonstraram que houve diferença $(\mathrm{p}<0,05)$ de todos marcadores metabólicos avaliados durante os diferentes períodos do ciclo produtivo, indicando que houve variação na disponibilidade de alimento, possivelmente capaz de gerar perdas produtivas e reprodutivas que podem ser solucionadas com suplementação proteica ou melhoramento do campo nativo.

\section{Introdução}

Nos sistemas de cria e ciclo completo, os touros compóem uma importante categoria, seja para utilização em programas de inseminação artificial ou em sistema de monta natural ${ }^{1}$. Trata-se de uma categoria animal que possui efeito direto no melhoramento genético de um rebanho, já que um touro é responsável por servir um determinado número de fêmeas, dependendo do manejo adotado na propriedade, deixando um maior número de descendentes do que uma fêmea ${ }^{2}$.

Dentre os inúmeros fatores que afetam o desempenho reprodutivo de bovinos, a nutrição é um dos que têm o maior impacto, tendo influência direta na liberação de hormônios gonadotróficos como o LH e o $\mathrm{FSH}^{3}$. Inúmeras pesquisas têm demonstrado que o estado nutricional e metabólico do animal influencia suas funçóes reprodutivas ${ }^{4,5}$.

Em sistemas de produção baseados em campo nativo, um dos principais problemas encontrados é a sazonalidade de produção desse recurso, sendo causado principalmente, pelas variaçóes climáticas, o que pode determinar ineficiência nos índices produtivos ${ }^{6,7}$. Segundo González ${ }^{8}$, janeiro e junho seriam os meses com maior deficiência de substratos proteicos na dieta, sendo maior em junho. Lobato ${ }^{7}$ relata que o fator mais limitante na produção pecuária é a deficiência nutricional do campo nativo no período hibernal, aliado à ausência de práticas 
de manejo que permitiriam uma melhor e mais eficiente utilização do mesmo.

Para a avaliação do perfil metabólico considerando os níveis dos marcadores bioquímicos e suas possíveis interaçóes no desempenho produtivo e reprodutivo podem ser avaliados, a glicose e o colesterol como marcadores energéticos, ureia e albumina proteicos e a enzima aspartato aminotransferase (AST) como marcador da função hepática ${ }^{6,9,10,11,12}$. Tais avaliaçóes permitem avaliar o ingresso, egresso e a metabolização dos nutrientes nos tecidos animais ${ }^{6,13}$. Normalmente a estação reprodutiva no Rio Grande do Sul é programada nos meses em que a oferta alimentar é mais adequada, havendo maior disponibilidade de forragem no campo nativo, de maneira que o início da estação reprodutiva ocorra no o final da primavera e o término, no final do verão ${ }^{14}$. Outro motivo para que seja definido este período de estação reprodutiva é para que coincidam os nascimentos nas épocas de melhor oferta alimentar, determinando melhores condiçóes para que a vaca crie o terneiro e possa ter condições de repetir cria ${ }^{15}$. Em fêmeas, muitas interaçóes entre metabolismo e reprodução, bem como o estudo do perfil metabólico já foram estudadas, porém em touros existem poucos estudos correlacionando estas interaçôes.

A hipótese deste estudo é que existam variaçóes nos marcadores bioquímicos durante os três períodos distintos do ciclo reprodutivo, ou seja, no período pré-estação reprodutiva, durante e após a estação reprodutiva. Desta forma, o objetivo deste experimento foi avaliar o perfil metabólico de touros mantidos em campo nativo, durante três períodos distintos do ciclo reprodutivo, em que a oferta alimentar e a atividade reprodutiva desempenhada pelos animais são distintas.

\section{Materiais e Métodos}

O estudo foi realizado no município de Santa Vitória do Palmar - RS, com 23 touros de diferentes raças mantidos em campo nativo, sendo oito Aberdeen Angus, três Red Angus, seis Hereford e seis Limousin. Foi realizado ao início deste estudo o exame andrológico de todos os touros, a fim de determinar que animais com alteraçóes clínico reprodutivas não fossem incluídos no experimento ${ }^{16}$.

A avaliação do perfil metabólico aconteceu em três períodos, sendo definidos como períodos I, II e III, referentes ao período pré-estação, durante a estação e após estação reprodutiva, respectivamente. As avaliaçōes nestas três épocas foram realizadas com objetivo de contemplar diferentes ofertas alimentares e, ainda, avaliar o efeito das diferentes atividades, físicas e comportamentais, as quais os reprodutores foram submetidos nos diferentes períodos. Durantes as três coletas também foram realizados avaliação do escore de condição corporal de todos os animais, utilizando a escala de 1 a 5 (sendo $1=$ magro e $5=$ gordo $)^{17}$. Para avaliar os níveis de marcadores metabólicos de acordo com a condição corporal, os animais foram categorizados em dois grupos: condição corporal menor ou igual a $3(\leq 3)$ e maior que 3 (> 3). A definição dos intervalos das coletas foi organizada de acordo com o manejo adotado na propriedade, na qual a duração da estação reprodutiva foi de cinco meses, compreendendo os meses de dezembro a abril.

As coletas de sangue para avaliação do perfil metabólico foram realizadas nos seguintes meses: setembro, correspondendo ao período pré-estação reprodutiva; fevereiro, referente ao período de monta e junho, contemplando o período pós-estação. As amostras de sangue foram coletadas de todos os animais por meio de punçáo da veia jugular, sendo divididas em três frascos: frasco 1 , contendo anticoagulante (EDTA $10 \mathrm{~g} \%$ ) na proporção de $12 \mu \mathrm{L} / \mathrm{mL}$ de sangue; frasco 2, contendo EDTA $10 \mathrm{~g} \%$ e inibidor de via glicolítica (KF 12\%) na proporção de $12 \mu \mathrm{L} /$ $\mathrm{mL}$ e $16 \mu \mathrm{L} / \mathrm{mL}$ de sangue, respectivamente; frasco 3, sem anticoagulante. Após foram centrifugadas a $3500 \mathrm{rpm}$ durante 15 minutos e divididas em dois tubos tipo eppendorff previamente identificados, dos quais um foi congelado a $-20^{\circ} \mathrm{C}$ e o outro 
resfriado $\mathrm{a}+4^{\circ} \mathrm{C}$. A quantificação dos metabólicos foi realizada de acordo com os métodos colorimétricos através de kits reagentes específicos (LABTEST ${ }^{\oplus}$, Brasil), $^{2}$ com a utilização de espectrofotômetro de luz visível FEMTO $435^{\circ}$. Todas as avaliaçóes realizadas, incluindo exame andrológico e análise do perfil metabólico, foram executadas por técnicos previamente treinados.

O perfil energético foi determinado a partir das concentraçóes plasmáticas de glicose (método da glicose oxidase), nas amostras de plasma contendo fluoreto (KF $12 \%$ ) armazenadas nos eppendorffa $\pm 4^{\circ} \mathrm{C}$, já o colesterol foi determinado (técnica de colesterol oxidase) em amostras de soros congelados $\left(-20^{\circ} \mathrm{C}\right)$. A determinação do perfil proteico foi realizada através das concentraçóes de albumina (técnica do verde de bromocresol) e de ureia (técnica da urease) em soro refrigerado. A enzima AST foi determinada (técnica de Reitiman e Frankel) em plasma refrigerado.
As variáveis contínuas, que são os resultados de cada marcador bioquímico, foram analisadas por análise de variância e comparação entre médias de acordo com Teste de Tukey HSD $(\mathrm{p}<0,05)$ e a condição corporal que é uma variável categórica, foi analisada pelo teste de Qui-quadrado e Exato de Fischer utilizando o software Statistix 8 for Windows $^{18}$.

\section{Resultados e Discussão}

Durante as três fases do ciclo reprodutivo, embora as avaliaçóes metabólicas de glicose, colesterol, albumina, ureia e AST estivessem de acordo com os padróes fisiológicos para a espécie bovina $^{19}$, foram observadas diferenças nas suas concentrações. Os valores médios encontrados para cada marcador durante os três períodos estão demonstrados na tabela 1 .

Tabela 1- Concentrações médias ( \pm erro padrão) dos marcadores bioquímicos avaliados durante os três diferentes períodos do ciclo reprodutivo de touros

\begin{tabular}{lccc}
\hline Marcadores Bioquímicos & Período I & Período II & Período III \\
\hline Glicose mg/dL & $31,91 \pm 2,63^{\mathrm{b}}$ & $28,01 \pm 1,85^{\mathrm{b}}$ & $47,52 \pm 1,71^{\mathrm{a}}$ \\
Albumina mg/dL & $2,16 \pm 0,04^{\mathrm{a}}$ & $1,65 \pm 0,04^{\mathrm{b}}$ & $1,75 \pm 0,05^{\mathrm{b}}$ \\
Ureia mg/dL & $30,14 \pm 0,96^{\mathrm{a}}$ & $11,95 \pm 0,74^{\mathrm{c}}$ & $19,19 \pm 0,71^{\mathrm{b}}$ \\
Colesterol $\mathbf{~ m g / d L}$ & $106,27 \pm 5,64^{\mathrm{ab}}$ & $112,78 \pm 4,83^{\mathrm{a}}$ & $89,87 \pm 3,80^{\mathrm{b}}$ \\
AST UI/L & $41,02 \pm 0,60^{\mathrm{c}}$ & $45,84 \pm 0,69^{\mathrm{b}}$ & $49,43 \pm 0,66^{\mathrm{a}}$ \\
\hline
\end{tabular}

Letras diferentes na mesma linha diferem pelo teste de Tukey HSD $(p<0,05)$

Os níveis de glicose durante as duas primeiras coletas mantiveram-se estabilizados, sendo que na última coleta a sua concentração apresentou-se elevada ( $\mathrm{p}$ $<0,05)$. Possivelmente, esta elevação tenha sido causada pela distância percorrida pelos animais até o local de contenção, para que fossem realizados os procedimentos de coleta de sangue, já que neste período os animais eram mantidos em piquetes mais distantes do centro de manejo, devido à disponibilidade de forragem. Outro ponto a ser considerado é que nas outras duas coletas os animais foram trazidos até ao local de contenção, em média, 18 horas antes da coleta de sangue, proporcionando que a mobilização energética ocasionada pela locomoção fosse minimizada, normalizando os valores deste marcador. Isto se deve ao fato da glicose ser um marcador muito sensível ao estresse, devido ao fato de o organismo animal possuir vários mecanismos para que seus níveis mantenham-se estabilizado ${ }^{19}$. Condição de hipoglicemia somente será observada em condições de severo balanço energético negativo ${ }^{8}$, o que náo foi constatado nestes animais nos diferentes períodos. 
A albumina, que é a principal proteína plasmática, sendo responsável por $80 \%$ da osmolaridade do plasma sanguíneo, é um dos marcadores bioquímicos do perfil proteico. Sua concentração pode ser influenciada pelo funcionamento hepático, a disponibilidade de aminoácidos e perdas durante doenças, principalmente em parasitismos gastrintestinais ${ }^{20}$. De acordo com os resultados (Tabela 1), mesmo sendo um marcador estável, a concentração de albumina foi maior no período pré-estação $(\mathrm{p}<0,05)$, possivelmente pelo melhor aporte proteico na dieta, já que nos outros dois períodos a concentração reduziu e se manteve estável. Segundo Payne e Payne ${ }^{13}$ para se detectar mudanças significativas na concentração sérica de albumina é necessário o período de um mês, devido a sua baixa velocidade de síntese e de degradaçáo em ruminantes, fato que pode ser observado durante os diferentes períodos de coleta (Tabela 1).

A ureia também é um indicador do nível proteico administrado na dieta e sua concentração é proporcional à quantidade de amônia produzida no rúmen ${ }^{21}$. Em relação aos valores de ureia (Tabela 1), podem-se observar resultados superiores no período I em relação aos outros dois períodos $(\mathrm{p}<0,05)$, provavelmente pelo melhor nível proteico na dieta, já que este marcador está diretamente relacionado ao nível de degradaçáo proteica, ou seja, seráo encontrados valores altos de ureia em situaçóes de excesso de proteína na dieta ou em situaçóes de grave balanço energético negativo em que esteja ocorrendo degradação proteica como fonte de energia ${ }^{22}$, o que não foi observado neste caso. No período II, a queda mais acentuada nos valores de ureia (tabela 1) pode ser justificada pelo aumento na atividade desempenhada pelos animais, já que este período compreende o período de monta com gasto de energia, associado à queda na qualidade da dieta, principalmente em relação à fonte proteica ${ }^{23,24}$, o que também pode ser observado pela redução dos níveis de albumina. De modo geral, a ureia é um indicador sensível e imediato da ingestão de proteína, enquanto que a albumina é um indicador mais estável, ocorrendo queda em suas concentraçóes somente em situaçóes de longos períodos de déficit proteico na dieta ${ }^{22}$, como podemos verificar nos resultados, ocorrendo uma maior variação nos níveis de ureia em relação à albumina, durante os três períodos.

Os níveis de colesterol, que é o precursor dos hormônios esteróides ${ }^{25}$, diferiram numericamente nos dois últimos períodos em relação ao período I (Tabela 1), sendo encontrada a concentraçáo mais baixa no período III, possivelmente pela baixa disponibilidade de alimentos ricos em energia. Considerando que machos com baixos níveis energéticos na dieta podem apresentar diminuição nos níveis de testosterona plasmática $^{26}$, os níveis observados poderão influenciar a fertilidade destes animais. Os resultados encontrados no período II (estação reprodutiva) demonstraram aumento da concentração de colesterol contradizendo um trabalho conduzido com fêmeas ${ }^{27}$, que observou redução dos níveis de colesterol, pela manutenção dos níveis de progesterona pelo corpo lúteo, durante o período de maior atividade luteal (diestro) do ciclo estral. Já neste estudo, durante o período de estaçáo reprodutiva em que possivelmente ocorreria maior síntese de hormônio esteróide e, consequentemente, diminuiçáo de colesterol, não foi observada tal redução nos seus níveis.

Em relação à enzima hepática AST, que é uma enzima indicadora da função dos hepatócitos, foi observada variação entre as coletas $(\mathrm{p}<0,05)$, demonstrando um aumento gradativo na concentração (Tabela 1), mas de acordo com os padróes fisiológicos. $\mathrm{O}$ aumento gradativo dos níveis dos marcadores provavelmente deve ter sido desencadeado pela diminuiçáo na qualidade da dieta e, consequentemente, aumento da função hepática, principalmente no período III com o aumento da metabolização da albumina, já que foi observado decréscimo na sua concentração em relação ao período I. A importância do monitoramento da função hepática é justificada por este órgão 
participar de atividades metabólicas vitais, incluindo a atividade reprodutiva, sendo um dos principais órgãos produtores de IGF-I (fator de crescimento semelhante à insulina I), que possui efeito direto na fertilidade dos machos $^{28}$.

Em relação à condiçâao corporal, que é um dos indicadores de reserva energética dos animais ${ }^{29}$, não foi encontrada diferença significativa entre os três períodos distintos (Tabela 2) demonstrando que a condição corporal manteve-se estabilizada. Poucos estudos relacionando condiçáo corporal, fertilidade e condição metabólica de touros foram desenvolvidos. Já em fêmeas foram realizados estudos demonstrando que vacas com baixa condição corporal apresentaram queda na taxa de prenhez, maior intervalo entre partos e maior incidência de transtornos metabólicos ${ }^{13,30,31,32}$. As concentraçôes médias de marcadores metabólicos correspondentes às condiçóes corporais estáo apresentados na tabela 3 , não havendo diferença entre animais com condição corporal $\leq 3$ ou $>3(\mathrm{p}>0,05)$, devido a maioria dos touros apresentar condição corporal 2 ou 3 (Tabela 2), não havendo grande discrepância entre as suas reservas corporais.

Tabela 2- Frequência (\%) das condições corporais de touros em três diferentes períodos do ciclo reprodutivo

\begin{tabular}{lccc}
\hline Condição Corporal & Período I $(\mathbf{n}=\mathbf{2 3})$ & Período II $(\mathbf{n}=\mathbf{2 3})$ & Período III $(\mathbf{n}=\mathbf{2 1})$ \\
\hline $\mathbf{1}$ & 4,3 & 4,3 & 0 \\
$\mathbf{2}$ & 47,8 & 47,8 & 42,8 \\
$\mathbf{3}$ & 43,5 & 43,5 & 57,2 \\
$\mathbf{4}$ & 4,3 & 4,3 & 0 \\
\hline
\end{tabular}

Não foram observadas diferenças estatísticas ( $p>0,05)$ pelo teste de Qui-Quadrado

Tabela 3- Concentrações médias ( \pm erro padrão) dos marcadores bioquímicos de touros de acordo com a condição corporal

\begin{tabular}{lcc}
\hline \multirow{2}{*}{ Marcadores Bioquímicos } & \multicolumn{2}{c}{ Condição Corporal } \\
\cline { 2 - 3 } & $\mathbf{3}$ & $>\mathbf{3}$ \\
\hline Glicose $\mathbf{~ m g / d L}$ & $34,48 \pm 2,26$ & $36,93 \pm 2,15$ \\
Albumina mg/dL & $1,84 \pm 0,06$ & $1,87 \pm 0,05$ \\
Ureia mg/dL & $21,51 \pm 1,55$ & $19,62 \pm 1,47$ \\
Colesterol mg/dL & $101,17 \pm 4,55$ & $95,88 \pm 4,32$ \\
AST UI/L & $44,68 \pm 0,87$ & $46,07 \pm 0,83$ \\
\hline
\end{tabular}

Não foram observadas diferenças estatísticas $(p>0,05)$ pelo teste de Tukey HSD

Neste estudo pode ser observado que as alteraçôes nos marcadores metabólicos avaliados náo foram suficientes para que ocorressem alteraçóes na estrutura corporal dos animais. As diferenças encontradas nos marcadores bioquímicos avaliados, possivelmente foram causadas pela diferença na oferta alimentar nos distintos períodos, o que pode gerar prejuízos nos índices produtivos e reprodutivos, sugerindo que seja realizado um planejamento nutricional para os touros com a utilização de soluçóes alimentares tais como, suplementaçáo proteica ou melhoramento do campo nativo ${ }^{33}$.

\section{Conclusão}

De acordo com os resultados deste estudo pode-se constatar que ocorreram variaçóes de todos marcadores bioquímicos avaliados durante os diferentes períodos do ciclo reprodutivo de touros mantidos em campo nativo, mesmo que de acordo com os padróes fisiológicos.

\section{Agradecimentos}

Este experimento foi realizado com o apoio do CNPq e Labtest ${ }^{\oplus}$. 


\title{
Evaluation of the metabolic profile of bulls in different phases of the reproductive cycle
}

\begin{abstract}
Bulls are an important category in cattle production systems, being responsible for a considerable part of genetic improvement in a herd. However, few studies about the metabolic conditions of this category have been done. The objective of this study was to evaluate the metabolic profile of bulls in three different phases of the reproductive cycle, that are, before, during and after the breeding season. This study was conducted with 23 bulls, in a farm in southern Rio Grande do Sul. The biochemical markers used for the evaluations were: glicose and cholesterol, to determine energetic profile; albumin and urea to determine protein profile and enzyme aspartate aminotransferase (AST) as an indicator of liver functionality. There was a difference $(\mathrm{p}<0,05)$ in all metabolic markers evaluated during the different phases of the productive cycle, showing that there was a variation in food availability, which could lead to productive and reproductive losses. This could be improved by protein supplementation and pasture improvement.
\end{abstract}

\section{Referências}

1 NICHI, M.; BOLS, P. E. J.; ZÜGE, R. M.; BARNABE, V. H.; GOOVAERTS, I. G. F.; BARNABE, R. C.; CORTADA, C. N. M. Seasonal variation in semen quality in Bos indicus and Bos taurus bulls raised under tropical conditions. Theriogenology, v. 66, n. 4, p. 822-828, 2006.

2 VENTER, H. A. W. Importância da maturidade sexual precoce e da idade ao primeiro parto no gado de corte. Belo Horizonte: Colégio Brasileiro de Reprodução Animal, 1982. p. 453-459.

3 BRITO, L. F. C.; BARTH, A. D.; RAWLINGS, N. C.; WILDE, R. E.; CREWS, J. R.; DENNY, H.; MIR PRIYA, S.; KASTELIC, J. P. Effect of nutrition during calfhood and peripubertal period on serum metabolic hormones, gonadotropins and testosterone concentrations, and on sexual development in bulls. Domestic Animal Endocrinology, v. 33, n. 1, p. 1-18, 2007. Disponível em: http://www.journals.elsevierhealth. com/periodicals/dae. Acesso em: 4 out. 2006.

4 HAMMOND, J. The physiology of reproduction in the cow. London: Cambridge University Press, 1972. p. 35-70.

5 ROBINSON, J. J. Nutrition and reproduction. Animal Reproduction Science, v. 42, n. 1, p. 25-34, 1996.

6 CONTRERAS, P. A. Indicadores do metabolismo protéico utilizados nos perfis metabólicos de rebanhos. In: GONZÁLEZ, F. H. D.; BARCELLOS, J.; PATIÑO, H. D.; RIBEIRO, L. A. (Ed.). Perfil metabólico em ruminantes: seu uso em nutrição e doenças nutricionais. Porto Alegre: UFRGS, 2000. p. 23-30.
Keywords:

Bulls.

Metabolic profile.
7 LOBATO, J. F. P. Pastagens melhoradas e suplementação alimentar no comportamento reprodutivo de vacas de corte primíparas. Revista Brasileira Zootecnia, v. 27, n. 1, p. 47-53, 1998.

8 GONZALEZ, F. H. D. Uso do perfil metabólico para determinar o status nutricional em gado de corte. In: GONZÁLEZ, F. H. D.; BARCELLOS, J. O.; OSPINA, H.; RIBEIRO, L. A. O. (Ed.). Perfil metabólico em ruminantes: seu uso em nutrição e doenças nutricionais. Porto Alegre: UFRGS, 2000. p. 28-45.

9 GUÉDON, L.; SAUMANDE, J.; DUPRON, F. COUQUET, C.; DESBALS, B. Serum cholesterol and triglycerides in postpartum beef cows and their relationship to the resumption of ovulation. Theriogenology, v. 51, n. 7, p. 1405-1415, 1999.

10 KAPPEL, L. C.; INGRAHAM, R. H.; MORGAN, E. B.; ZERINGUE, L.; WILSON, D.; BABCOCK, D. K. Relationship between fertility and blood glicose and cholesterol concentrations in Holstein cows. American Journal of Veterinary Research, v. 45, n. 12, p. 2607-2612, 1984.

11 LAGO, E. P.; PIRES, A. V.; SUSIN, I.; FARIA, V. P.; LAGO, L. A. Efeito da condição corporal ao parto sobre alguns parâmetros do metabolismo energético, produção de leite e incidência de doenças no pós-parto de vacas leiteiras. Revista Brasileira de Zootecnia, v. 30, n. 5, p. 1544-1549, 2001.

12 PEIXOTO, L. A. O.; BRONDANI, I. L.; NÖRNBERG, J. L.; RESTLE, J.; ALVES, D. C.; PAZINI, F. M.; CORADINI, M. T.; SANTOS, C. V. M. Perfil metabólico protéico e taxas de concepção de vacas de corte mantidas em pastagem natural ou suplementadas com 
farelo de trigo com ou sem uréia. Ciência Rural, v. 36, n. 6 , p. 1873-1877, 2006.

13 PAYNE, J. M.; PAYNE, S. The metabolic profile test. Oxford: University, 1987. p. 170.

14 SOUZA, R. M.; FILAPPI, A.; PRESTES, D.; LISTON, M. A.; ANTONIAZZI, A.; CECIM, M. Perfil protéico e eficiência reprodutiva de vacas de corte em lactação suplementadas com uréia no verão. Archives of Veterinary Science, v. 9, n. 2, p. 89-93, 2004.

15 SILVA, A. W. L. Taxas de reconcepção e intervalo parto-concepção influenciados pela sub-época e mês de parição de vacas de corte. 1989. 79 f. Dissertação (Mestrado em Agronomia) - Universidade Federal do Rio Grande do Sul, Porto Alegre, RS, 1989

16 MORAES, J. C. F. Predição da fertilidade de touros empregados em monta natural. In: CONGRESSO BRASILEIRO DE REPRODUÇÃO ANIMAL, 1995, Belo Horizonte. Anais... Belo Horizonte, 1995. v. 1, p. 287.

17 LOWMAN, B. G.; SCOTT, N.; SOMERVILLE, S. Condition scoring beef cattle. Edingburgh: East of Scotland College of Agriculture, 1976. p. 8. (Bulletin, 6).

18 STATISTIX $^{\circledR}$. Statistix for Windows User's Manual. Tallahassee: Analytical Software, 2003.

19 KANEKO, J. J. Clinical biochemistry of domestic animals. 5. ed. San Diego: Academic Press, 1997. 932 p.

20 ROWLANDS, G. J. A review of variations in the concentrations of metabolites in the blood of beef and dairy cattle associated with pathology, nutrition and disease, with particular reference to the interpretation of metabolic profiles. World Review of Nutrition and Dietetics, v. 35, p.172-235, 1980.

21 WITTNER, F.; REYES, J. M.; OPITZ, H. Determinacion de úrea muestras de leche de rebaños bovinos para el diagnóstico de desbalance nutricional. Archivos de Medicina Veterinária, v. 25, p. 165-172, 1993.

22 GONZÁLES, F. H.; SILVA, S. C. Introdução à bioquímica clínica veterinária. Porto Alegre: UFRGS, 2003. 198 p.

23 JACQUES, A. V. A. Potencialidades das pastagens do Rio Grande do Sul visando à intensificação da pecuária. In: LOBATO, J. F. P.; BARCELLO, J.; KESSLER, A. M. (Ed.). Produção de bovinos de corte. Porto Alegre: EDIPUCRS, 1999. p. 67-76.
24 KAPP, O.; MOLETTA, J. L.; STRACK, A. G.; BREN, L. Influência do uso do sal mineral proteinado sobre a produção de carne em pastagem de Hemarthria altíssima cv. Flórida. In: REUNIÃO ANUAL DA SOCIEDADE BRASILEIRA DE ZOOTECNIA, 2001, Piracicaba. Anais.. Piracicaba: FEALQ, 2001. p. 1249-1250.

25 GRUMMER, R. R.; CARROLL, D. J. Effects of dietary fat on metabolic disorders and reproductive performance of dairy cattle. Journal of Animal Science, v. 69, p. 3838-3852, 1991.

26 NOLAN, C. J.; NEUENDORFF, D. A.; GODFREY, R. W.; HARMS, P. G.; WELSH JR., T. H.; MCARTHUR, N. H.; RANDEL, R. D. Influence of dietary energy intake on prepubertal development of brahman bulls. Journal Animal Science, v. 68, n. 4, p. 1987-1996, 1990.

27 TALAVERA, F.; PARK, C. S.; WILLIAMS, G. L. Relationship among dietary lipid intake, serum cholesterol and ovarian function in Holstein heifers. Journal Animal Science, v. 60, n. 4, p. 1045-1051, 1985.

28 SIROTKIN, A. V. Control of reproductive processes by growth hormone: extra- and intracellular mechanisms. The Veterinary Journal, v. 105, n. 3, p. 307-317, 2004.

29 SPITZER, J. C.; MORRISON, D. G.; WETTEMANN, R. P.; FAULKNELS, L. C. Reproductive responses and calf birth and weaning weights as affected by body condition at parturition and postpartum weight gain in primiparous beef cows. Journal Animal Science, v. 73 , n. 5, p. 1251-1257, 1995.

30 PATTON, R. A.; BUCHOLTZ, H. F.; SCHMIDT, M. K. Body condition scoring: a management tool. Michigan: Dairy Guide, East Lansing, 1988. p. 6.

31 RICHARDS, M. W.; SPITZER, J. C.; WARNER, M. B. Effect of varying levels of postpartum nutrition and body condition at calving on subsequent reproductive performance in beef cattle. Journal Animal Science, v. 62, p. 300-306, 1986.

32 SELK, G. E.; WETTEMANN, R. P.; LUSBY, K. S.; OLTJEN, J. W.; MOBLEY, S.L.; RASBY, R.J.; GARMENDIA, J. C. Relationships among weight change, body condition and reproductive performance of range beef cows. Journal Animal Science, v. 66, p. 3153-3159, 1988.

33 ANDERSON, S. J.; KLOPFENSTEIN, T. J.; WILKERSON, V. A. Escape protein supplementation of yearling steers grazing smooth brome grass pastures. Journal of Animal Science, v. 66, p. 237-242, 1988. 